\title{
Designing for the Infrastructure of the Supply Chain of Malay Handwoven Songket in Terengganu
}

\author{
Min Zhang \\ Lancaster University \\ Lancaster, UK \\ m.zhang18@lancaster.ac.uk
}

\author{
Corina Sas \\ Lancaster University \\ Lancaster, UK \\ c.sas@lancaster.ac.uk
}

\author{
Zoe Lambert \\ Lancaster University \\ Lancaster, UK \\ z.lambert@lancaster.ac.uk
}

\author{
Masitah Ahmad \\ Universiti Teknologi MARA \\ Malaysia \\ masitah@ns.uitm.edu.my
}

\begin{abstract}
The growing $\mathrm{HCI}$ interest in developing contexts and cultural craft practices is ripe to focus on their underexplored homegrown sociotechnical infrastructures. This paper explores the creative infrastructural actions embedded within the practices of songket's supply chain in Terengganu, Malaysia. We report on contextual interviews with 92 participants including preparation workers, weavers, designers, merchants, and customers. Findings indicate that increased creative infrastructural actions are reflected in these actors' resourcefulness for mobilizing information, materials, and equipment, and for making creative artifacts through new technologies weaved within traditional practices. We propose two novel approaches to design in this craft-based infrastructure. First, we explore designing for the social layer of infrastructure and its mutually advantageous exploitative relationships rooted in culture and traditions. Second, we suggest designing for roaming value-creation artifacts, which blend physical and digital materializations of songket textile design. Developed through a collaborative and asynchronous process, we argue that these artifacts represent less-explored vehicles for value co-creation, and that sociotechnical infrastructures as emerging sites of innovation could benefit from HCI research.
\end{abstract}

\section{CCS CONCEPTS}

- Human-centered computing • Human-centered computing $\sim$ Human computer interaction (HCI) Empirical studies in $\mathrm{HCI}$

\section{KEYWORDS}

Infrastructure; HCID; crafts; songket; cultural heritage; gender

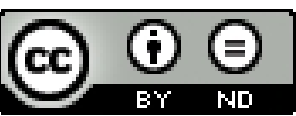

This work is licensed under a Creative Commons Attribution-NoDerivs International 4.0 License.

(C) 2019 Copyright is held by the owner/author(s).

ACM ISBN 978-1-4503-5970-2/19/05.

DOI: https://doi.org/10.1145/3290605.3300716

\section{ACM Reference format:}

Min Zhang, Corina Sas, Zoe Lambert and Masitah Ahmad. 2019. Designing for the Infrastructure of the Supply Chain of Malay Handwoven Songket in Terengganu. In 2019 CHI Conference on Human Factors in Computing Systems Proceedings (CHI 2019), May 4-9, 2019, Glasgow, Scotland, UK. ACM, NY, NY, USA. Paper 486, 14 pages. https://doi.org/10.1145/3290605.3300716

\section{INTRODUCTION}

$\mathrm{Che} \mathrm{Ku}$ weaves on her grandmother's wooden loom in the front porch of her house. Just down the road, her son is building his own home, supported by her earnings. She is the fourth generation of weavers in her family, and she had often watched her mother and grandmother as they weaved the fine threads using the traditional patterns they knew by heart. Che Ku was twelve the first time she sat down at the wooden loom. Weaving was already in her blood. Until a few years ago, she worked for a merchant who supplied her with the threads, the design papers, and the warp boards prepared by another woman. The merchant paid a small amount for her labor, which was never enough for the one or two months it took her for each piece. But when her husband became seriously ill, she applied for a government business grant to buy her own threads and materials. Now, she owns her own business, outsources the work to other skilled village people and finds her customers. She has regular customers in the local market, but she also sells to a merchant in Kuala Lumpur the songket fabric that is made to order from unique designs. She posts pictures of songket on Facebook and Instagram, and uses WhatsApp to communicate with customers, but a relationship needs to be set up and maintained, preferably over an iced coffee. Once established, trust is never broken. Che $\mathrm{Ku}$ is a part of the emerging rural entrepreneurial weavers in Malaysia who just like seasoned merchants are starting to use mobile and social media technologies for these daily exchanges of their business. 


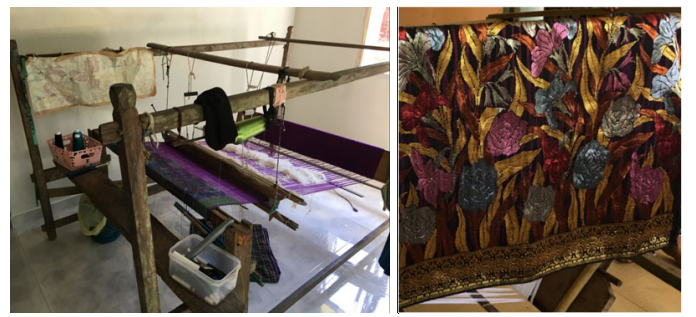

Figure 1. Songket handloom in a weaver's house (left); A Songket fabric (right)

Songket is a woven fabric handcrafted for more than two centuries in South Asia, where the knowledge and skills of hand weaving have been passed down through generations [52]. This unique fabric is woven on a handloom by inserting the colored metallic threads through the silk or cotton threads [33,52] (Figure 1). While traditionally, songket fabric was worn by royalty and court members [52], today, the exclusive design of handmade songket makes it a desirable fabric worn by most Malaysians at special occasions [34]. Despite its demand, handmade songket weaving is an increasingly endangered practice due to the machine-made songket rising in international South Asia market, and the decreasing interest of younger generations in learning the craft $[33,40]$.

We argue that the growing $\mathrm{HCI}$ interest in developing contexts, cultural heritage, crafts and practices offers a fertile, yet under-explored research space. Of particular interest here is the investigation of local infrastructure supporting this practice, and the emerging roles of mobile and social network technologies transforming it. The grassroots integration of new tools into traditional cultural practices has just started to be explored with findings indicating resourceful and creative infrastructural actions for online selling and buying of ready-made consumer goods in developing contexts [19]. We argue that infrastructures also supporting the making of products, particularly cultural heritage ones such as songket, can offer fresh insights into such creative actions. In turn, these could inform more sensitive approaches for designing technologies that could be seamlessly weaved within such creative infrastructures in developing contexts. In this paper, we report interviews with 92 participants representing key actors in songket's supply chain in Terengganu, Malaysia, well-known for its songket's unique colors, motifs, and quality [15]. We interviewed 28 rural weavers, 26 merchants, 6 songket designers, 2 preparation workers, 3 government staff working on songket-related programs, and 27 customers. Our study addresses the following research questions:
- What are the novel tools that these key actors are engaging with?

- What creative infrastructural actions do each of the main actors engage with in order to integrate these new tools within the songket's supply chain?

- What challenges do these actors face and how could these be addressed?

\section{RELATED WORK}

For this work, we draw from prior research on developing contexts and cultural heritage, crafts, and practices in HCI.

\subsection{HCI for Developing Contexts}

HCI for developing contexts (HCID) [2,4] is a growing research area exploring how technologies can contribute to global socioeconomic development [55] by addressing the needs of marginalized populations [6]. Much of such work has focused on the support for economic empowerment particularly of rural women [17], provision of education and health [24], development of local infrastructure [19], or preservation of cultural heritage [53]. Previous work has also emphasized the value of information and communication technologies (ICTs) and in particular mobile phones [24] for sustainable development [56] through the increase of the labor market [35], and more effective communication infrastructures [21,26]. ICTs also contribute to women's empowerment [35] by facilitating the selling of crafts. Internet sites such as ONE store ${ }^{1}$ and Indigo Africa ${ }^{2}$ support women makers to bring their sweetgrass baskets onto the global online market. Such interventions require sensitive design as women in impoverished contexts are particularly challenged when it comes to access ICT-based support [25,29], due to limited confidence, skills, or their time often filled by domestic demands [29].

Apart from scholarly work targeting specific technological solutions, an emerging HCID research agenda argues for engaging with the creation of sociotechnical infrastructures $[7,22,23,32,45,46]$. Such work emphasizes the importance of local physical environment and human infrastructure [44] and the sensitivity needed to account for the cultural asymmetry between the Western researchers and targeted population in these developing contexts [51,57]. Jack and colleagues [19] explored such an infrastructure of online selling shops in the capital city of Cambodia [19], which integrates Facebook and mobile

\footnotetext{
${ }^{1}$ https://one.shop.musictoday.com/store/

${ }^{2}$ https://indegoafrica.org/
} 
payment system with older tools such as paper receipts, feature phones, public buses, and motorcycle delivery services. Authors argued for the value of exploring such homegrown sociotechnical systems where people show resourcefulness and creativity in integrating novel technologies into older cultural practices [19]. We agree with the importance of studying these organically emerging infrastructures in order to inform more responsible design of HCID technologies. Our study extends Jack and colleagues' [19], moving the focus on creative infrastructural actions from online selling and buying of ready-made consumer goods to the distributed making, selling, and buying of indigenous heritage crafts.

\subsection{Crafts and Practices in $\mathrm{HCl}$}

A growing body of HCI work has examined the digital innovation within traditional handicraft, both within Western [11,13,37,54] and developing contexts [53,64]. Such work has explored digital technologies for accessing and storing tangible and intangible cultural heritage [13], particularly in interactive museums [37] to support richer user engagement. Other researchers argued for increasing cultural identity [53] in order to protect cultural heritage. For example, Tan and Blevis prototyped a system to assist villagers to build pride in cultural craft by integrating maps with QR narratives of the craft [53]. With respect to the cultural heritage of songket fabric, Zhang and colleagues [64] conducted interviews with weavers in rural Malaysia. Their findings indicate key actors in songket making practices and the challenges faced by different types of weavers. With its emphasis on weavers, their work sheds little light on the infrastructure of songket's supply chain, or on how key actors engage in creative actions integrating new tools within this traditional practice.

Another rich strand of HCI work has focused on practice-based approaches to research and design [38]. In such work, practice is defined through bodily activities and physical objects [39], or people's competencies of interacting with specific materials through which they develop meaning [8]. While much work has focused on the DIY practices of making and repairing of both nonelectronic [58] and electronic devices [42,47], other scholars have looked at traditional handicrafts such as weaving [43] or knitting [41] with the intention of unpacking their material qualities and their value for the development of hybrid computational objects [48]. Such practice and materiality-based approaches of situated crafts have started to challenge the distinction between the individual and the social, the physical and the digital context [48]. New hybrid computational objects have been designed to explore the augmentation of traditional craft practices with computational capabilities. For example, Stitch Sampler is a sew-able musical instrument and craft platform that generates digital tones during hand-sewing when the needle enters the fabric [48], while Spyn allows integrating digital messages within the specific places within the knitted fabric, in order to support knitters' communication and reflection on their practices [42]. Another example is Electronic Quilt, materializing the invisible work of female weavers for dense storage of information on so-called core memory, i.e., the array of magnetic ferrite, a practice consisting of passing a wire through or around magnetized cores [43].

Such illustrative projects suggest an emphasis on digitally augmented craft practices, usually in Western contexts where they are pursued mostly for pleasure, communication, and reflection purposes. However, we know little of how similar gendered craft practices such as songket weaving are digitally augmented in the organically emerging sociotechnical infrastructures in developing contexts, serving more utilitarian functions such as earning an income, empowering women, or preserving cultural heritage.

\section{METHODOLOGY}

The study was conducted over one year within nine villages in Terengganu and involved contextual semi-structured interviews with 92 participants: 28 weavers (26 female, 2 male; age range 25-80, median 45), 26 merchants (20 female, 6 male; 32-75, 50.5), 6 songket designers (4 female, 2 male; 27-64, 36), 2 preparation workers (2 female; 50-56, 53), 3 local government staff working on songket-related programs ( 2 female, 1 male; 42-55, 43), and 27 customers (22 female, 5 male; 18-59, 43). All participants were educated at the primary school level and above, and owned a mobile device. Half of the weavers and all other participant groups use smartphones (age range 25-45, median 39). All participants except $47 \%$ of weavers have access to the Internet on their mobile devices. The majority of rural weavers $(83 \%)$ have bank accounts, but only $8 \%$ have online payment experience.

Weavers, merchants, preparation workers, songket designers, and craft-related government staff were recruited with the help from the national handicraft government sector Kraftangan and its local branch in Terengganu. Customers were recruited in carnivals and shops in Kuala Lumpur, or via the emailing system and whiteboard posters at the Universiti Teknologi MARA. In order to become "familiar faces" and "trusted intermediaries" [5], prior to 
completing the interviews, Malay researchers engaged in multiple visits to participants' sites between spring 2017 and summer 2018. These contextual interviews were conducted face-to-face in Malay language in participants' preferred settings such as weavers' and designers' houses, merchants' shops or workshops, or customers' houses or offices. Such contextual interviews also allowed for the observation of the songket making practices, including preparation work, songket textile design, and weaving. In addition, in the presence of a Malay researcher, the first author also performed interviews with 7 weavers with passion for songket heritage and entrepreneurial activities, and conducted observation at the local marketplace in Terengganu over two days. Interviews lasted around two hours, were audio recorded, translated, and fully transcribed in English; each participant was rewarded RM 50.

In order to explore the value of technology for the songket's supply chain and its practices, we asked each actor group about their materials, tools, and logistics. We also inquired about their motivations for engaging in songket practices, their challenges, and perspective regarding the songket practice in Malaysia. The first author also conducted online ethnography on the Facebook and Instagram accounts of 26 merchants, with a focus on updates and photos posted during the study. Data analysis was led by the UK researchers and involved standard inductive-deductive techniques of coding [10], consisting of literature-based codes, i.e., stakeholders, types of weavers and their challenges, and materials, codes which were iteratively revised through weekly face-to-face meetings among UK researchers, and fortnight Skype meetings with Malay researchers. The latter meetings were crucial to ensure sensitivity of the data interpretation within the Malay context, and the agreement of the inductive codes emerging from the interviews around the specific practices of songket design, making, and distribution.

\section{CONTEXT}

Terengganu is one of the three states of the East coast of Peninsular Malaysia, and is inhabited by 1.2 million people. With a predominant agriculture-based economy, the region experiences a high incidence of lower income and poverty compared to the country [50]. Although the Malay culture is collectivist and patriarchal [16], previous work suggested a rather high status of women in Peninsula Malaysia as they tend to be economically active in trade and agricultural production [18]. With a steady annual growth, the importance of the textile industry has been recognized through increased governmental investment [30]. This has also focused on skill training for rural development, including Terengganu, which is recognized for the quality of its distinct songket design [15]. Despite such initiatives, most songket weavers are women in rural areas earning low income, often below the poverty line [50]. Similar to the rest of Malaysia, Terengganu shows high cellular phone penetration rate, which however is lower in rural areas [28] where feature phones tend to be used mostly for texting and phone calls. With connectivity available nationwide, Internet use is also high, particularly for social networks such as Facebook and Instagram, with e-commerce remaining considerably lower in rural areas [29]. Although people between 20 and 39 years old show increased interest in technology adoption, those over 40 show less [29]. While most Malay people own a bank account, those in rural areas make little use of online payment [14].

\section{FINDINGS: SONGKET'S SOCIOTECHNICAL INFRASTRUCTURE}

This section describes the songket's supply chain and its infrastructure. We illustrate the findings with quotes from participants' interviews, C1-C27 for customers, D1-D6 for designers, G1-G3 for government staff, M1-M26 for merchants, W1-W28 for weavers, and P1-P2 for preparation workers. We now provide an overview of findings, followed by a description of the social actors and the power asymmetry among them, and a detailed presentation of the processes involved in the songket's supply chain. Study findings focus on how Malaysians use ICTs and social media technologies for songket's supply chain and its practices. A striking finding, however, is the high number of diverse materials and tools that many social actors engaged with within the infrastructure. Such materials and tools represent a creative blend of traditional ones such as handlooms and other small equipment, as well as threads, dyes, papers showing songket design, feature phones, and contemporary ones such as computers, smartphones or tablets. Within the supply chain, raw materials such as threads and dyes are bought mostly in local shops but also online through websites such as Aliexpress, which provide delivery services and online payment facilities. Songket weaving also requires equipment such as a wooden warp board which is bulky and heavy, hence bought mostly from local villagers for which people tend to pay cash, and travel to collect by cars.

Apart from these raw materials and equipment, another material serving as input into the songket making process is the songket design consisting of motifs of stylized local flora. This is a creative artifact that tends to be outsourced to 
skilled artisans, and travels among other actors throughout the entire supply chain. Songket design is materialized into different forms: hand drawings on grid papers, computersupported drawings, copies and prints of drawings on grid paper, or embedded within the warp board and finally songket fabric. As a precious textile that people prefer seeing and touching before buying, songket's practices are arguably strong candidates for resisting technology adoption. The buying and selling of songket takes place either online but mostly in physical marketplaces or shops, or at national craft venues such as carnivals. A growing number of merchants have a presence on Facebook or Instagram for their individual business to showcase their songket stocks, and on WhatsApp to engage privately in one-to-one communication with their customers. People bargain and barter, and after the agreement is reached, payment tends to be made via bank transfer, while the delivery is done by courier services such as POS express. Most Malaysians still use the cash payment, as "the material supplier will trust cash more than credit card or other transfer such as check" [W27]. For logistics that facilitate the movement of these tangible materials and products among the actors, people rely on public or personal transportation including buses, private cars or motorbikes, with private vehicles being preferred due to the underdeveloped transport system. They also rely on delivery services such as POS express, or if they can afford, flying to the customer's place to deliver the most expensive songket fabric.

\subsection{Actors within the Songket's Supply Chain}

We now offer an overview of the key social actors within songket's supply chain. An important finding is that besides the clear division of labor among the traditional roles such as weavers, merchants, and customers, new actors and their roles become apparent throughout our study, although these have been limitedly mentioned in the state-of-the-art. Thus, we extended the study by also interviewing preparation workers, designers, and government staff working on songket-related programs. Actors are not homogeneous, including distinct subgroups with different motivations for engaging in songket practices, and different competencies to work with its materials and tools. For example, our findings confirm the previous distinction between end weavers, commission weavers, and entrepreneurial weavers [64]. This taxonomy reflects an increased autonomy from end weavers to entrepreneurial ones, as the latter benefit from the capital to purchase raw materials, the ability to travel and to find customers, and subsequently to make a profit from other weavers' work.
Another important finding that received little attention in previous work is weavers' competencies: while all can complete basic songket weaving involving 2-3 colors, a smaller number of weavers have both the competencies and the motivations of engaging in high-end songket weaving involving more than 5 colors and bespoke motifs. While the basic songket takes about 3-4 weeks to complete, the highend songket takes about 6 weeks. Weaver's income for one piece of basic songket is between RM 500-800, while for the latter is RM 1800-2000. Based on the size of their business, findings also indicate two types of merchants. Small-scale merchants have a smaller customer base and a smaller pool of weavers working for them (1-10), and tend to buy their materials and sell the songket locally. Large-scale merchants have a larger customer and weaver base (at least 30 ), even a workshop or shop, and normally buy materials and sell songket both locally, but also nationally and even internationally.

Songket designer is a particularly interesting role of which we know little from previous work. Usually commissioned by merchants, designers prepare bespoke designs either with traditional or contemporary motifs. Such creative work requires high-level skills together with the knowledge and respect for the cultural heritage of songket weaving. Our findings emphasize designers as important actors within the songket practices, as about half of songket fabric sold on the market have been woven based on bespoke designs ordered by customers either for basic or high-end songket. Designers tend to work between 3 and 10 days on one design and are paid RM 80-400, and this role can be played by established weavers, experienced merchants, or young people with an interest in songket and increased digital literacy.

Findings indicate another distinct role mentioned by both merchants and weavers, namely the preparation workers, who prepare the warp threads, wind the bobbins and warp frame, warp threads to warp board, insert threads through the reeds, and tie the buttons to shift patterns from paper to threads. These steps require distinct skills and special equipment such as a warp table and thread winder, and as a result, they are often performed by different professional workers other than the weavers [31].

Our infrastructure approach to the exploration of songket practices through interviews and observations of multiple actors has broadened the understanding of such materials beyond the songket weaving, extending it towards both its preparation and distribution channels. This, in turn, allowed the identification of a richer and more nuanced flow of materials and information among the key 
actors, and how different technologies become organically appropriated to assist this flow. Such appropriation extends the use of already adopted technologies such as smartphones and popular social networks, i.e., Facebook, WhatsApp, and Instagram, for everyday exchanges required by songket practices. Key roles of such ICTs and social media platforms include supporting the ongoing coordination of actors' actions before, during, and after the songket handcrafting.

\subsection{Infrastructure's Materials}

We now describe the key elements within the supply chain such as materials and equipment involved in the design, making, and distribution of songket. The raw materials used for songket production include cotton or silk, and colored metallic threads, dyes, together with specific equipment consisting of handloom, warp board (warping threads on the frame), and other small pieces of equipment such as shuttles and reeds. Such equipment tends to be handmade by local villagers, durable and can be used for a long time (i.e., 40 years). Most merchants purchase threads and dyes from local shops. With regard to provenance, such threads are either made locally, or imported from China, Japan or Thailand: "most of the raw materials can be found in a Chinese shop at Kuala Terengganu" [M10]. Most purchases of these raw materials are made through face-toface transactions, collection in person by merchants or their employees [M5, M8], and transportation by one's car. Such purchases could also be delivered to merchants' places through delivery services such as POS express, albeit these tend to be expensive [M12]. Large-scale merchants are most likely to engage in online purchases of raw materials, usually in bulk from China: "yarns made in China are much cheaper comparing to other countries" [M4, M16-18]. While online shopping comes at a lower cost, it also comes with constraints regarding minimum order: "some sellers require bulk orders of at least 10 tons" [M18]. The delivery of such larger orders of threads is usually done by lorries [M17], whose cost is offset by the reduced price of the bulk order [M16].

Weavers' access to the raw materials is limited [W1, W8], occurring mostly when they are asked to weave for their community, i.e., family or friends. In such rare cases, they may travel by car or motorbike to the local shop to buy threads for which they pay cash. Some weavers may be also entrusted by the merchant to purchase threads from their local shops for which they receive advance cash [W20].

\subsection{Songket Design}

Songket design is crucial not only for weavers but also for the preparation workers who need to count on the design while tying the buttons on the threads. The songket design is separated into three parts: head, body, and foot [34,52]. Designs could be created by merchants, designers, or weaver's family members or friends.

5.3.1 Songket Designer. Designers have specialized skills and this role tends to be performed by experienced weavers or merchants. Preparation workers can also do such design work. However, if other designers focus primarily on the songket body, preparation workers can also focus on the design of motifs and patterns for songket head and foot [P1]. Outsourced songket design will take between 3 and 7 days to complete, with costs between RM 80-400, depending on the complexity of the motif. Therefore, both professional designers and preparation workers usually keep the design paper in a portfolio (Figure 2, left) for reuse. Designers can also be younger people with an interest in songket who also have design skills. They could also be government staff working on songket-related programs. For example, such designers in Kraftangan engage in computer generated songket design using, for example, Microsoft Paint or Adobe Photoshop/Illustrator. Their aim is to create innovative designs, both traditional and contemporary, that are shared at no cost with merchants registered with the Kraftangan Malaysia. The digitalization of songket designs offers the advantage of being quickly produced. In order to be shared with other actors, such designs need to be printed on a large grid paper [D1] (Figure 2) via special printers available in shops or cybercafe. Some merchants also have their own printers and provide the physical design paper to preparation workers or weavers, who can carefully count 'dots' on the grid paper to move motifs onto warp boards, or weave them.
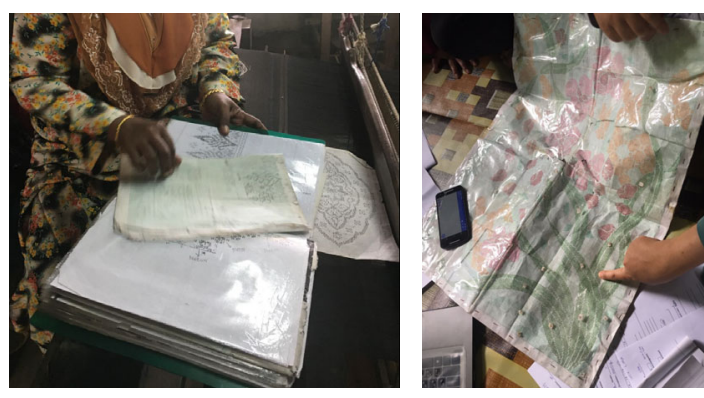

Figure 2. Preparation worker showing her designs (left); Weaver showing a protected paper-based design (right).

Interestingly, most weavers have limited input into the songket design, as their job often starts after the design is completed. Sometimes, they are offered the choice of 
designing the more structured part of the songket, i.e., head and foot, which many of the wavers enjoy; they tend to use traditional motifs such as mangosteen and bamboo shoot. Weavers have tacit knowledge of the basic traditional motifs so that they seldom exterrnalize such designs by drawing them on paper [W6-7, W9]. Although some weavers also have more complex knowledge required for designing songket body, they seldom do so as "it is really hard to make, especially for the exclusive songket" [W20], where a high level of creativity is required: "it is really hard to come out with new designs" [W16, W21]. Therefore, only a few designers are able to take on these tasks for high end bespoke songket [W19].

5.3.2 Bespoke Design. Findings indicate customers' preferences for bespoke songket designs, as $89 \%$ mentioned that they are not happy to wear a songket fabric with the same design as others. Most customers tend to travel to merchants' to discuss such preferences. Customers' inspiration for such design comes from online photos of songket [C11] or by browsing through the songket fabrics showcased in the merchants' shops or market stalls [C4]. Apart from such face-to-face interaction, the communication between customers and merchants regarding the bespoke design can also take place remotely through phone calls as well as through WhatsApp for sharing the photos about the desired design [C15, C24]. Such communication may require several exchanges to ensure that customer's requirements are understood [C16] and to avoid mistakes [C3], especially for expensive songket. Sometimes, customers provide drawings for merchants to understand their requirements [C9, C15].

Customers need to pay a deposit when they place the bespoke order. High-end customers engage differently in this activity: they tend to call merchants to bring songket fabrics to their houses or offices [M6]. By browsing these samples, these customers work with the merchants to cocreate new bespoke designs. Usually, merchants sketch the design for the customer [C27] and refine it based on the customer's direct feedback [C28]. Apart from this direct involvement in the creation of the bespoke design, other customers are happy to entrust their merchants to come up with the songket design [W12]. In most cases, customers will request the background color, so that it matches the color of the event where they will wear the songket [C2, C6, C21, C23, C28]. For instance, "during Eid Mubarak celebration, my family will choose one color theme to wear" [C6, C23]. Customers' preferences vary from traditional to more contemporary motifs [C23, C26]. Weavers seldom get involved in bespoke design: "I do not design. I do not want to make a wrong songket" [W21]. The customer requirements travel among different actors many times. "Sometimes, my merchant provides me with a sample or picture of songket, then she will ask me to find the designer, so I just pass it to my friends then my friends will design it for me" [W29]. However, the design requirements are communicated verbally through face-to-face communication. Since it is difficult to describe the desired color in language, "sometimes, it is hard to achieve what customers want" [W25].

5.3.3 Design Paper. The design paper is normally a $74 \mathrm{~cm} \mathrm{x}$ $50 \mathrm{~cm}$ grid paper. For contemporary body design which tends to be asymmetric, the design paper is fully covered by dots, while for head, foot, and traditional body design, only one repeated unit is needed to be drawn or copied on A3 or A4 grid paper. Because many songket pieces can be made based on one design with different colors, the design paper can be reused many times, maybe by different weavers. After preparation work and songket weaving are completed, merchants come to the artisan's place to collect the products and design paper, then allocate the desgin paper to different artisans. Sometimes, design paper with the new design is protected by a plastic cover (Figure 2, right), to guard the fragile design paper and to indicate color codes of different motifs. Some designers photocopy the design on white paper in town's cybercafes. The copy of the design is sold to merchants at a lower price. Merchants bring the copy of the design to different weavers, who decide the colors of motif combination. To protect the design, some designers leave their names under their designs [D6]. Some weavers mentioned that "the design paper must be destroyed after the design is used" [W15], and often weavers are expected to keep the design confidential: "weavers will hold the secrecy to us. So, they will never leak any information" [M26]. Although weavers or merchants claimed that each songket is unique [W6, W15], our observation and interviews indicate that most merchants lack "brand uniqueness" since they may buy the designs from the same designers. Only large merchants are able to hire designers and mark designs under their business brand [M14].

\subsection{Songket Making}

Apart from design, songket making involves collaborative work of both preparation workers and weavers. Both activities are intricate and labor-intensive requiring attention to details and patience [W15, W22], often considered feminine virtues [31]. Findings suggest strong ambivalence towards the songket craft, although an icon of local cultural heritage [52]: "there are no other places that 
can produce songket like us [in Terengganu]" [M16], many weavers lack the incentive to preserve the craft: "my mother does not really encourage me to do songket; not big money. She rather encourages me to go to school and get a formal education to get a good job" [W4]. These quotes indicate merchants' more positive perception of the value of songket craft than weavers' perceptions.

\subsubsection{Mutually Beneficial Exploitative Relationships between} Weavers and Merchants. We now describe the rather complex relationships between weavers and their merchants, built on trust and loyalty over generations: " $m y$ mother also dealt with merchant's mother in the same way in the past, I just continue this tradition" [W6]. Many merchants claim that they treat weavers as their own relatives, for example, helping single-mothers [M14] or the jobless younger people by offering them training and songket orders [M8, M11, M13]. In addition, weavers are always paid, sometimes in advance [M14], even when occasionally their weaving has imperfections [W6]. In turn, weavers are grateful: "I know her [the merchant] since young; we are really close. I consider her as my sister because she always helps me when I have no money. I believe that she can help my family" [W18]. As a result, most weavers are motivated to work for merchants. First, they appreciate that this can ensure a consistent source of income, advance payment when needed [M14], as well as protection from the risk of dealing with bad customers: "there are buyers who asked to take the songket first, but never come back to pay. With a merchant, I can guarantee I get the money" [W6]. Second, weavers, especially the older ones, are happy to trade their low-paid income for flexible working hours: " $m y$ body hurts when I sit on the handloom consistently for a long time. So I only work for two hours in the morning and afternoon" [W20]. Third, because of domestic labor [W18], most weavers have limited mobility to travel for work outside the house. Thus, they are happy to trade off the low paid income for the flexibility of working from home: "working in the city is difficult because I have small kids and his brother is still in school, so I decide to learn to weave and work from home" [W29]. Such positively portrayed relationships are abundant in participants' answers reflecting also the Malay collectivist culture, where respect for authority is valued. Despite this level of care, weavers' work takes place through informal casual contracts with limited welfare provision for retirement, maternity, or illness. In particular, women weavers who need to take a few-year break to raise their infants run the high risk of not resuming their work, as the merchant will choose other available weavers to replace them. For example, M2 used to be a home-based weaver who could no longer weave at the normal speed after delivering a baby, and subsequently, the merchant refused to give her any further songket orders. However, due to her husband' illness, she had to support the whole family and hence started to become an entrepreneurial weaver. A few participants also provide accounts suggesting that these relationships are in fact exploitative: "the merchants will be unhappy if they know weavers sell songket by themselves" [W8, W16-17]. We now describe different activities involved in the songket making.

5.4.2 Preparation Work. The preparation for the weaving process is laborious and requires specialist skills, therefore, few weavers are competent and interested in doing it. Thus, merchants usually commission such jobs to skilled preparation workers. Merchants bring the warp boards (reusable), threads and design (a piece of grid paper or just a piece of songket sample) to preparation workers' house by car. Sometimes preparation workers themselves buy the warp boards and threads from local markets or shops, and the merchants refund their costs. When the preparation work is finished (normally in one week), the preparation worker contacts the merchant by mobile phone, arranging for the latter to collect (usually by car) the ready-to-weave warp boards from the preparation worker's house with cash payment. The large business merchants hire their own preparation workers, especially for expensive Limar songket.

5.4.3 Weaving. After the preparation work is completed, merchants bring the warp board and other small pieces of equipment, design paper, and threads, even the handloom [W2, W19, W21, W29], to weavers' houses by car. During the process of weaving, merchants or their representatives regularly (once or twice a week) check the progress and quality by visiting weavers' houses, with the aim to eliminate mistakes at an early stage. Although the conversations between merchants and weavers tend to be face-to-face, sometimes merchants commission the check of songket's quality and its progress to local master weavers, or ask the weaver to take photos of their work in progress and to send them via WhatsApp.

The time taken for weaving one piece of songket fabric depends on the pattern, motif, and color of the design, as well as the weaver's skills. For example, one piece with a simple design and silk background will take one month to complete; an intricate design may take 2 months. Cotton warp is easier to weave than silk, so it takes less time because "silk is very fragile and soft" [W2] and more concentration is required [W9]. Weavers will work harder to complete one piece of songket quickly when they need money urgently [W6-W8]. Some weavers also run other 
jobs such as selling household goods [W18] or sewing [W20], and their merchants are happy to accommodate longer completion time [W16, W18]. After a piece of songket is completed, weavers notify merchants by phone or on WhatsApp in order to agree on the collection date. Weavers will spend another few days to finish the songket by cutting the end threads before merchants come to pay and collect it. The weaver is normally paid RM 500-2000 for one piece of songket, depending on its complexity. The income from songket weaving is often used to pay for a house or car [W4-5,W15], household expenses [W3,W14], or children's education [W6-9, W15].

5.4.4 Authentication of Cultural Heritage Handicraft. To control the quality of handmade songket, government authority developed standards for authenticating it. The assessment service is freely offered to anyone who would like to apply, and the test contains 8 steps such as measuring the size of fabric, the density of threads, the color/light/wash/water/perspiration/friction resilience. People whose songket fabric passes the assessment will get free "Authentic Songket Terengganu" labels (Figure 3, left) and certificates (Figure 3, right). However, only a few merchants apply for these, because the assessment process requires cutting a songket fabric into small strips therefore destroying the fabric [D1]. In addition, merchants who already have customers' trust no longer need such certificates, unless they want to attract new customers [M25]. An interesting finding is that while small-scale merchants sew the label onto the edge of songket fabric when requested by customers, large merchants sew it together with their own brand logo promoting their business.
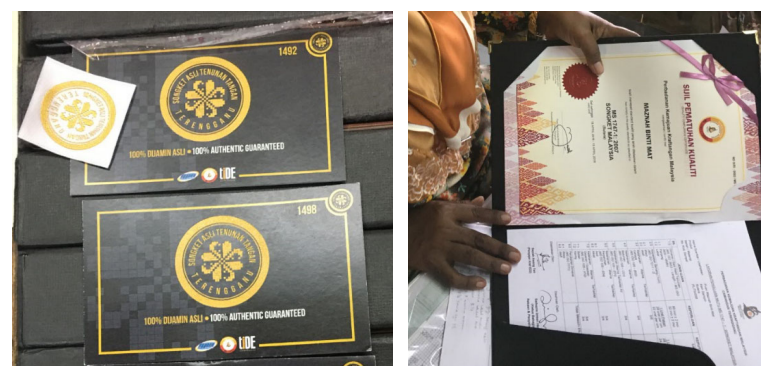

Figure 3. "Authentic Songket Terengganu" labels (left) and certificate (right) shown by a merchant in Pasar Payang.

5.4.5 Government Support. To preserve the cultural heritage, the government established a National Handicraft Institute to provide formal training for songket making and entrepreneurship [D6]. However, the effectiveness of such training has been questioned [M11], as only a small number of people usually complete it [52].

\subsection{Songket Distribution}

Various actors such as merchants, local or urban retailers, or local government or NGO staff contribute to the songket distribution, each with their own channels and marketing strategies. Unlike these actors, home-based weavers only occasionally sell to their own customers [W4, W15, W24, W26], usually reached through family or friends: "I have customers from fohor and Kuala Lumpur, who come here and never ask for discounts because they know the normal price is higher in the market. So I can sell them at a higher price than I get from my merchant" [W15]. Findings indicate clear differences between new-starter entrepreneurs and established merchants, with the latter having stronger customer base, weaver workforce, and reputation. Because songket weaving takes time, with the average weaver being able to complete no more than 12 pieces with a simple design a year, and 5-6 pieces with complex bespoke design, this amount is not enough for a weaver to start selling in a market stall, where merchants' tend to hold stock of at least 100 pieces of songket. The novice entrepreneurs also sell the products to retailers or big merchants. For retailers, entrepreneurs call the shopkeeper to ask about their needs of stock, and after they agree on the price and delivery date, entrepreneurs will send the songket to retailers' stores by cars.

Some merchants travel by car and sell songket door-todoor, while a few have their own shops in the city [M16, M22] or local markets such as Pasar Payang (Figure 4) [M5, M8, M17]. Another popular channel to get new customers is to attend carnivals [M14] that are two-week events organized by the local government or NGOs throughout the year to promote handicrafts. However, only merchants registered with the local government or NGOs are invited to attend, and their costs for renting a stall are subsidized by the government.

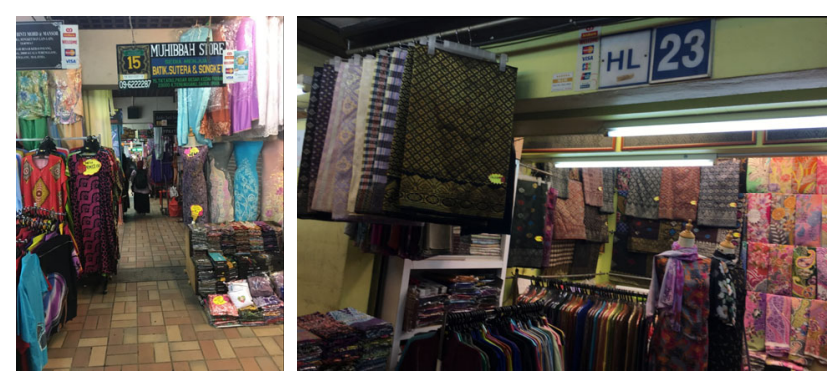

Figure 4. The songket Pasar Payang market in Kuala Terengganu, the capital of Terengganu state.

5.5.1 Social Media Promotion Channel. Findings indicate that many merchants make use of social media such as Facebook (70\%), WhatsApp (75\%), and Instagram (30\%) for online songket promotion [M1, M9-10, M12, M14, M16-17, M19]. 
We also looked at merchants' online profiles promoted on Facebook: this reveals its use as an online shopping service for which, however, online payment is poorly supported. Malay customers have three options of payment for online shopping: cash on delivery, bank transfer, or check. Online payment tends to be used only when the trust between customers and merchants has been established [C21]. On Facebook or Instagram, customers can make comments to review songket items, while communicating or bargaining directly with the seller takes place mostly through WhatsApp or Facebook's private Messenger. Merchants also build their own customer networking via WhatsApp group [M14], to promote new products and customer care. It is indicated that middle- and upper-class Malaysians are more likely to order the songket fabric with a customized design. Usually, such high-end songket fabric is delivered to customer's house who will pay cash. However, given the large amount of money involved, such payment can also be digital, as some merchants bring along a card reader to enable payments by credit card [C21] or via online bank transfer.

5.5.2 Trust that Customers Build on Merchants. Despite the lack of standardization of songket production, customers deeply trust the songket's quality, based on merchants' reputation [C6] with whom they continue to engage in the repeated transactions: "customers normally go directly to famous sellers and even pay a higher price" [W15]. Such a reputation may be inherited from the family business: "which has sold songket for a long time; there are no problems in terms of trusting them" [W26]. In such contexts, it is easy to see the challenges faced by a weaver who would like to become entrepreneur.

\section{DISCUSSION}

Our exploration of the Malay handmade songket's supply chain and its organically emerging sociotechnical infrastructure extends HCI recent insights into similar infrastructures in developing contexts [19]. However, while previous work has focused on infrastructural actions of online selling and buying of imported consumption goods, our study explores an infrastructure involving a richer network of actors (merchants, designers, preparation workers, weavers, and customers) focusing not only on the online selling and buying but also on the making of heritage artifacts. Without a central infrastructure designer, these diverse and actors geographically distributed in local villages and cities, capital, or even overseas are particularly resourceful in mobilizing their flow of information, materials, equipment, and creative cultural heritage artifacts. Alongside the traditional approaches consisting mostly of face-to-face communication and cash as a payment instrument, these actors seamlessly have started to integrate in their practices new devices and technologies across the entire supply chain. These include smartphones, computers, and social media technologies such as Facebook, WhatsApp or Instagram to promote the songket products and communicate with customers, online buying of threads, Microsoft Paint for songket design, digital payment for threads and songket fabric, and courier services for songket delivery.

A key finding is that this technological layer emerges from within a long established social infrastructure shaped by traditions and culture. Thus, social actors such as weavers, preparation workers, designers, and merchants are hierarchically organized in a pyramid structure (Figure 5), with merchants (not weavers) benefiting from the highest level of mobility, skills, knowledge about the market, visibility on the market, and capital.

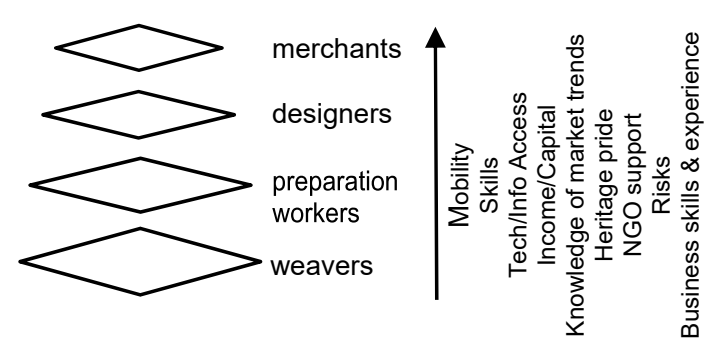

Figure 5. Actors in the songket's production chain.

Findings indicate the invisibility of rural weavers in both the physical world, and the digital sphere, as their relationships with customers are predominantly mediated by the merchants. Such invisibility of craft workers and their forms of production has been previously suggested together with their limited control over the distribution chain [49]. Our findings also confirm weavers' limited awareness of their vulnerable position, because of their longstanding relationships with the merchants [31].

Findings also indicate that weaving is a gendered practice shaped by a range of factors contributing to rural weavers' economic vulnerability such as high demands of reproductive labor that limits their mobility from home, limited education and access to alternative jobs, as well as lack of ownership of their means of production, i.e., raw materials and equipment. These factors have led to the commodification of their labor for which weavers benefit from limited welfare provision [62]. They are also unfairly paid merely subsistence wages with a disproportionately large share of the surplus value appropriated by the 
merchants (up to 8-10 times more for high-end bespoke songket). In addition, many merchants operate as monopoly providers of songket orders in a specific village, usually through strong historic roots and tacit claims over the exclusivity of their weavers' labor power. The paradox of exploitation characterizing merchant-weavers relationships is interesting and requires careful consideration. Indeed, despite their rather exploitative nature [27] these relationships are in fact consensual and perceived as beneficial by most weavers. Our findings thus extend the concept of care for the customers, highlighted as relevant to sociotechnical infrastructures in developing contexts [20] to include also care for makers. The latter is fundamental in infrastructures focusing on making, as it contributes to what appears to be mutually advantageous exploitative relationships. Wertheimer [60] described these relationships through offers which can make one better off than without, albeit worse than what one is entitled to from a fair share of the surplus. While such relationships received less attention in HCID, we argue that they should be considered [12] while designing for economic justice in developing contexts.

We argue for a departure from the Western-centric design for such contexts and their relationships, and towards a more encompassing global HCI, grounded both in local values [1] and HCI global ethics. For this, we can draw from ethics research about the grounds which might "justify interfering with consensual and mutually advantageous exploitative transactions" [61]. Soft paternalism [3] is one such approach consisting of informing the disadvantaged of the less exploitative, available transactions, such as in our case, weavers' option to weave for their own customers. Any such technological solutions will increase weavers' visibility in the market. However, it will also need to account for the fact that gaining independence from the merchant takes time; and that in order to protect weavers from the risks of wage loss, such solutions should harmoniously coexist for a while alongside the current exploitative relationships. Designing for such solutions will go beyond technical innovation as it may also require rethinking the role of the merchant in these more fair relationships and potentially new business models supporting such roles. Mutually exploitative relationships can also be positioned in the longstanding debate between global and local values. Here, we advance the HCI argument of cultural relativity $[1,36,63]$ which requires blending respect for human life with sensitivity to cultural differences in order to better understand developing contexts rather than impose neoliberal global values when designing for infrastructures in such contexts.
The approach described above is one possible way of addressing Monteiro and colleagues' question of how to move from design of artifacts to design of infrastructure [32]. To acknowledge however the absence of a central designer, we propose instead the design for infrastructure, and besides the approach outlined above which focuses mostly on the social relationships within the infrastructure and their inequalities, our findings indicate another approach. This focuses on the technological design for a key value-creation artifact within the infrastructure of songket's supply chain, namely the bespoke textile design of songket fabric.

An important outcome is that this highly creative product emerges through extensive collaborative design practices bringing together pairs of social actors: most often the merchant with each of the others, i.e., customer, designer, preparation worker, and weaver, respectively. Designed collaboratively and asynchronously through an iterative process, the songket creative design is both tacit and tangible. Hence, it becomes progressively materialized in different forms: computer-aided design (using Microsoft Paint or Adobe Illustration/Photoshop), collections of photos, hand-drawings on grid paper, copies or prints of these drawings, embedded within the warp board, and ultimately within the woven songket fabric.

Such design artifacts and the design knowledge underpinning them travel in all these forms among the infrastructure's social actors. Similar to Jack [19], our findings also indicate that this blend of physical and digital materials used to communicate the songket design is brittle [59]. For instance, hand-drawn designs may incompletely capture customer requirements, while creating bespoke designs from customer's preferred songket pictures is problematic. In addition, printed designs are fragile requiring protection from theft and natural elements, the warp board offers a physical footprint of the design, which is too large to store, being thus often destroyed to protect the design, while songket's authentication is appropriated by the merchant rather than the weaver.

We argue that such value-creation artifacts are key for the infrastructures focused on the production of crafts, and that they have qualities seldom recognized by the traditional HCI design approaches. Borrowing from the concept of roaming objects [9] as interactive systems for resource sharing in groups such cooperatives, we argue for the importance of designing roaming value-creation artifacts, which we define as hybrid objects that can better support the capture, co-creation, selective sharing, and protection of the outcomes of the collaborative design 
practices taking place in such infrastructures. Roaming value-creation artifacts are crucial for shaping such craftbased infrastructure as sites for collective innovation, with the potential to further challenge the binary division $[19,48]$ between the practices of physical and digital design. Finally, we acknowledge the complexity of designing for infrastructures and encourage HCI researchers to further engage with this underexplored and exciting space. Future work could explore new design methods to co-design for infrastructures in developing contexts, and of new HCI transnational research methods for capacity building.

\section{CONCLUSION}

Our extensive study investigates the emerging infrastructure for Malay handwoven songket's supply chain in Terengganu. The increased creative infrastructural actions found in songket's supply chain rely on the resourcefulness of its distributed actors in mobilizing information, materials, equipment, and craft products by integrating smartphones and social media technologies into their traditional practices. Our work advances the research agenda of shifting from artifact-focused design to infrastructure-focused design. Particularly for craft-based infrastructures, we suggest opportunities for HCI researchers to engage in the designing for its social layer of mutually advantageous exploitative relationships, and for roaming value-creation artifacts. The latter are key for supporting such organically grown infrastructures as emerging sites of innovation.

\section{ACKNOWLEDGMENTS}

This work was supported by Digital Threads: Towards personalized craft production in Malay cottage industries, funded by AHRC UK (Grant No. AH/P014186/1).

\section{REFERENCES}

[1] Fareda Banda. 2003. Global Standards: Local Values. Int. J. Law, Policy Fam. 17, 1 (April 2003), 1-27. DOI: https://doi.org/10.1093/lawfam/17.1.1

[2] Eric Brewer, Michael Demmer, Bowei Du, Melissa Ho, Matthew Kam, Sergiu Nedevschi, Joyojeet Pal, Rabin Patra, Sonesh Surana, and Kevin Fall. 2005. The case for technology in developing regions. Computer (Long. Beach. Calif). 38, 6 (May 2005), 25-38. DOI: https://doi.org/10.1109/MC.2005.204

[3] James D. Capozzi and Rosamond Rhodes. 2000. Paternalism. F. Bone ft. Surgery-American Vol. 82, 7 (July 2000), 1050-1051. DOI: https://doi.org/10.2106/00004623-200007000-00016

[4] Marshini Chetty and Rebecca Grinter Chetty. 2007. HCI4D: HCI Challenges in the Global South. In Proceedings of the $2007 \mathrm{CHI}$ Conference Extended Abstracts on Human Factors in Computing $\begin{array}{lllll}\text { Systems - } & \text { CHI } & & \\ & \end{array}$ https://doi.org/10.1145/1240866.1241002

[5] Andy Crabtree, Alan Chamberlain, Stela Valchovska, Mark Davies, Kevin Glover, and Chris Greenhalgh. 2015. "I've got a sheep with three legs if anybody wants it?":re-visioning the rural economy. Pers.
Ubiquitous Comput. 19, 8 (December 2015), 1247-1258. DOI https://doi.org/10.1007/s00779-015-0890-8

[6] Nicola Dell and Neha Kumar. 2016. The Ins and Outs of HCI for Development. In Proceedings of the 2016 CHI Conference on Human Factors in Computing Systems - CHI '16, 2220-2232. DOI: https://doi.org/10.1145/2858036.2858081

[7] W. Keith Edwards, Mark W. Newman, and Erika Shehan Poole. 2010. The infrastructure problem in HCI. In Proceedings of the 28th international conference on Human factors in computing systems - CHI '10, 423. DOI: https://doi.org/10.1145/1753326.1753390

[8] Jack Ingram Elizabeth Shove, Matthew Watson, Martin Hand. 2007. The Design of Everyday Life. Berg Publishers.

[9] Anton Fedosov, William Odom, Marc Langheinrich, and Ron Wakkary. 2018. Roaming Objects: Encoding Digital Histories of Use into Shared Objects and Tools. In Proceedings of the 2018 on Designing Interactive Systems Conference 2018 - DIS '18, 1141-1153. DOI: https://doi.org/10.1145/3196709.3196722

[10] Jennifer Fereday and Eimear Muir-Cochrane. 2006. Demonstrating Rigor Using Thematic Analysis: A Hybrid Approach of Inductive and Deductive Coding and Theme Development. Int. F. Qual. Methods 5, 1 (March 2006), 80-92. DOI https://doi.org/10.1177/160940690600500107

[11] Derek Foster, Ben Kirman, Conor Linehan, and Shaun Lawson. 2017 The role of social media in artisanal production: a case of craft beer. In Proceedings of the 21st International Academic Mindtrek Conference, 184-193. DOI: https://doi.org/10.1145/3131085.3131117

[12] Sarah Fox, Mariam Asad, Katherine Lo, Jill P. Dimond, Lynn S Dombrowski, and Shaowen Bardzell. 2016. Exploring Social Justice, Design, and HCI. In Proceedings of the 2016 CHI Conference Extended Abstracts on Human Factors in Computing Systems - CHI EA '16, 32933300. DOI: https://doi.org/10.1145/2851581.2856465

[13] Mónica Isabel González, Emilio Sánchez, and Edgar de los Santos 2011. ViTu: A System to Help the Mexican People to Preserve and Celebrate their Culture. In Proceedings of the 2011 annual conference extended abstracts on Human factors in computing systems - CHI EA '11, 971. DOI: https://doi.org/10.1145/1979742.1979502

[14] World Bank Group. 2017. Financial inclusion in Malaysia: Distilling Lessons for Other Countries.

[15] Muhammad Abi Sofian bin Abdul Halim and Azman Bin Che Mat. 2010. The contribution of heritage product toward Malaysian Tourism Industry: A case of eastern coastal of Malaysia. Int. F. Hum Sci. 7, 2 (2010), 346-357.

[16] Rahimah Hamdan and Shaiful Bahri Md.Radzi. 2014. The Meaning of Female Passivity in Traditional Malay Literature. Asian Soc. Sci. 10, 17 (August 2014), 222-228. DOI: https://doi.org/10.5539/ass.v10n17p222

[17] Fuzirah Hashim, Norizan Abdul Razak, and Zaini Amir. 2011. Empowering rural women entrepreneurs with ICT skills: An impact study of 1nita project in Malaysia. Procedia - Soc. Behav. Sci. 15, (2011), 3779-3783. DOI: https://doi.org/10.1016/j.sbspro.2011.04.373

[18] Charles Hirschman. 2016. Gender, the status of women, and family structure in Malaysia. Malaysian f. Econ. Stud. 53, 1 (2016), 33-50.

[19] Margaret Jack, Jay Chen, and Steven J Jackson. 2017. Infrastructure as Creative Action: Online Buying, Selling, and Delivery in Phnom Penh. In Proceedings of the 2017 CHI Conference on Human Factors in Computing Systems - CHI '17, 6511-6522. DOI: https://doi.org/10.1145/3025453.3025889

[20] Margaret Jack and Steven J. Jackson. 2016. Logistics as Care and Control: An Investigation into the UNICEF Supply Division. In Proceedings of the 2016 CHI Conference on Human Factors in Computing Systems - CHI '16, 2209-2219. DOI: https://doi.org/10.1145/2858036.2858503

[21] Shilpi Jain, Sriparna Basu, and Bishakha Majumdar. 2018. Digital Empowerment for Handloom Clusters: The case of Digital cluster Development Program in India. Int. J. Manag. Appl. Sci. 4, 1 (2018), 54-58.

[22] Irni Eliana Khairuddin and Corina Sas. 2019. An Exploration of Bitcoin mining practices: Miners' trust challenges and motivations. In Proceedings of the $2019 \mathrm{CHI}$ Conference on Human Factors in Computing Systems - CHI '19. 
[23] Irni Eliana Khairuddin, Corina Sas, Sarah Clinch, and Nigel Davies. 2016. Exploring Motivations for Bitcoin Technology Usage. In Proceedings of the $2016 \mathrm{CHI}$ Conference Extended Abstracts on Human Factors in Computing Systems - CHI EA '16, 2872-2878. DOI: https://doi.org/10.1145/2851581.2892500

[24] Siddique Latif, Rajib Rana, Junaid Qadir, Anwaar Ali, Muhammad Ali Imran, and Muhammad Shahzad Younis. 2017. Mobile Health in the Developing World: Review of Literature and Lessons from a Case Study. IEEE Access 5, June (2017), 11540-11556. DOI: https://doi.org/10.1109/ACCESS.2017.2710800

[25] Melissa Secore Levis. 2011. Working toward Women's Economic Empowerment: Using Information and Communication Technology in Developing Areas to Market Traditional Crafts. In HCI International, 266-273. DOI: https://doi.org/10.1007/3-540-68339-9_34

[26] Sylvia Maier and Usha Nair-Reichert. 2008. Empowering Women through ICT-Based Business Initiatives: An Overview of Best Practices in E-Commerce/E-Retailing Projects. Inf. Technol. Int. Dev. 4, 2 (January 2008), 43-60. DOI: https://doi.org/10.1162/itid.2008.00007

[27] Karl Marx. 1867. Capital: A Critique of Political Economy. C.H. Kerr and Company, Chicago.

[28] MCMC. 2015. Hand phone users survey 2014. DOI: https://doi.org/ISSN 1823-2523

[29] MCMC Survey. 2017. Internet Users Survey 2017.

[30] MITI. 2012. Third Industrial Master Plan (IMP2) 1996-2005, Textiles and Apparel Industry. Retrieved from www.ibef.org

[31] Maznah Mohamad. 1996. The Malay Handloom Weavers: A Study of the Rise and Decline of Traditional Manufacture. Institute of Southeast Asian Studies.

[32] Eric Monteiro, Neil Pollock, Ole Hanseth, and Robin Williams. 2013. From Artefacts to Infrastructures. Comput. Support. Coop. Work 22, 4-6 (August 2013), 575-607. DOI: https://doi.org/10.1007/s10606-0129167-1

[33] June Ngo Siok Kheng. 2007. Transforming Traditional Malaysian Songket into Contemporary Songket for Broader Apparel Usage. Universiti Sains Malaysia.

[34] June Ngo Siok Kheng. 2011. Revitalising the Craft of Songket Weaving through Innovation in Malaysia.

[35] Dagmara Nikulin. 2016. The impact of ICTs on Women's Economic Empowerment. DOI: https://doi.org/10.13140/RG.2.2.17805.54240

[36] Aihwa Ong. 2011. Translating Gender Justice in Southeast Asia: Situated Ethics, NGOs, and Bio-Welfare. Hawwa 9, 1 (January 2011), 26-48. DOI: https://doi.org/10.1163/156920811X575523

[37] Daniela Petrelli, Luigina Ciolfi, Dick van Dijk, Eva Hornecker, Elena Not, and Albrecht Schmidt. 2013. Integrating Material and Digital: A New Way for Cultural Heritage. Interactions 20, 4 (July 2013), 58-63. DOI: https://doi.org/10.1145/2486227.2486239

[38] James Pierce, Yolande Strengers, Phoebe Sengers, and Susanne Bødker. 2013. Introduction to the special issue on practice-oriented approaches to sustainable HCI. ACM Trans. Comput. Interact. 20, 4 (2013), 1-8. DOI: https://doi.org/10.1145/2494260

[39] Andreas Reckwitz. 2002. Toward a Theory of Social Practices. Eur. J. Soc. Theory 5, 2 (2002), 243-263. DOI: https://doi.org/10.1177/13684310222225432

[40] Marof Redzuan and Fariborz Aref. 2011. Constraints and potentials of handicraft industry in underdeveloped region of Malaysia. African J. Bus. Manag. 5, 2 (2011), 256-260. DOI: https://doi.org/10.5897/AJBM09.166

[41] Daniela K. Rosner and Kimiko Ryokai. 2008. Spyn: Augmenting Knitting to Support Storytelling and Reflection. In Proceedings of the 10th international conference on Ubiquitous computing, 340-349. DOI: https://doi.org/10.1145/1409635.1409682

[42] Daniela K. Rosner and Kimiko Ryokai. 2009. Reflections on Craft: Probing the Creative Process of Everyday Knitters. In Proceedings of the Seventh ACM Conference on Creativity and Cognition, 195-204. DOI: https://doi.org/10.1145/1640233.1640264

[43] Daniela K Rosner, Samantha Shorey, Brock R. Craft, and Helen Remick. 2018. Making Core Memory: Design Inquiry into Gendered Legacies of Engineering and Craftwork. In Proceedings of the 2018
CHI Conference on Human Factors in Computing Systems - CHI '18, 1-13. DOI: https://doi.org/10.1145/3173574.3174105

[44] Nithya Sambasivan and Thomas Smyth. 2010. The human infrastructure of ICTD. In Proceedings of the 4th ACM/IEEE International Conference on Information and Communication Technologies and Development - ICTD '10, 1-9. DOI: https://doi.org/10.1145/2369220.2369258

[45] Corina Sas and Irni Eliana Khairuddin. 2015. Exploring Trust in Bitcoin Technology: A Framework for HCI Research. In Proceedings of the Annual Meeting of the Australian Special Interest Group for Computer Human Interaction on - OzCHI '15, 338-342. DOI: https://doi.org/10.1145/2838739.2838821

[46] Corina Sas and Irni Eliana Khairuddin. 2017. Design for Trust: An Exploration of the Challenges and Opportunities of Bitcoin Users. In Proceedings of the 2017 CHI Conference on Human Factors in Computing Systems - CHI '17, 6499-6510. DOI: https://doi.org/10.1145/3025453.3025886

[47] Corina Sas and Carman Neustaedter. 2017. Exploring DIY Practices of Complex Home Technologies. ACM Trans. Comput. Interact. 24, 2 (2017), 1-29. DOI: https://doi.org/10.1145/3057863

[48] Sarah Schoemann and Michael Nitsche. 2017. Needle as Input: Exploring Practice and Materiality When Crafting Becomes Computing. In Proceedings of the Tenth International Conference on Tangible, Embedded, and Embodied Interaction - TEI '17, 299-308. DOI: https://doi.org/10.1145/3024969.3024999

[49] Timothy J. Scrase. 2009. From Marginalized Worker to Impoverished Entrepreneur: The Globalization of the Trade in Crafts and Its Impact on Indian Artisans. In Trade, Labour and Transformation of Community in Asia. Palgrave Macmillan UK, London, 102-126. DOI: https://doi.org/10.1057/9780230274105 5

[50] Zahari Siti Zalikha, Siwar Chamhuri, Idrus Shaharudin, and Idris Nor Diana Mohd. 2018. Poverty Mapping and Identifying the Hard-core Poor and Poor Group using Geographical Information System. Malay World Civilis. 6, Special Issue1 (2018), 87-94.

[51] Andy Smith and Lynne Dunckley. 1998. Issues for Human-Computer Interaction in Developing Countries. Retrieved from http://mikeb.inta.gatech.edu/uploads/LMI_files/papers/dunckley.pdf

[52] Suzanne Stankard. 2010. Textile Praxis: The Case for Malaysian Hand-Woven Songket. The Royal College of Art.

[53] Haodan Tan and Eli Blevis. 2017. Preserving Chinese Craft Heritage by Forging Rural-Urban Connections. In International Association of Societies of Design Research (IASDR) Conference.

[54] Ye Tao, Nannan Lu, Caowei Zhang, Guanyun Wang, Cheng Yao, and Fangtian Ying. 2016. CompuWoven: A Computer-Aided Fabrication Approach to Hand-Woven Craft. In Proceedings of the $2016 \mathrm{CHI}$ Conference Extended Abstracts on Human Factors in Computing Systems - CHI EA '16, 2328-2333. DOI: https://doi.org/10.1145/2851581.2892293

[55] Kentaro Toyama. 2010. Human-Computer Interaction and Global Development. Found. Trends Human-Computer Interact. 4, 1 (2010), 1-79. DOI: https://doi.org/10.1561/1100000021

[56] UNESCO. 2016. Global Report on Culture for Sustainable Urban Development Heritage and Creativity Culture. Retrieved from http://unesdoc.unesco.org/images/0024/002459/245999e.pdf

[57] Aditya Vashistha, Fabian Okeke, Richard Anderson, and Nicola Dell. 2018. 'You Can Always Do Better!" The Impact of Social Proof on Participant Response Bias Aditya. In Proceedings of the $2018 \mathrm{CHI}$ Conference on Human Factors in Computing Systems - CHI '18, 113. DOI: https://doi.org/10.1145/3173574.3174126

[58] Ron Wakkary, Audrey Desjardins, Sabrina Hauser, and Leah Maestri. 2013. A sustainable design fiction: Green practices. ACM Trans. Comput. Interact. 20, 4 (2013), 23. DOI: https://doi.org/10.1145/2494265

[59] Mark Warschauer and Morgan Ames. 2010. Can One Laptop per Child Save the World's Poor? J. Int. Aff. 64, 1 (2010), 33-51. DOI: https://doi.org/10.2307/24385184

[60] Alan Wertheimer. 1999. Exploitation. Princeton University Press, Princeton. 
[61] Alan Wertheimer and Matt Zwolinski. 2013. Exploitation. In The Stanford Encyclopedia of Philosophy, Edward N. Zalta (ed.). Metaphysics Research Lab, Stanford University. Retrieved from https://plato.stanford.edu/archives/sum2017/entries/exploitation/

[62] Eliza Wethey. 2004. Creative Commodification of Handicrafts, the Encounter between the Export Market and the Indigenous Weaver: Comparisons of Latin American Weaving Communities. Lambda Alpha 7. 35, May (2004), 2-28.
[63] Ben White. 1999. Defining the Intolerable: Child Work, Global Standards and Cultural Relativism. Childhood 6, 1 (February 1999), 133-144. DOI: https://doi.org/10.1177/0907568299006001010

[64] Min Zhang, Corina Sas, and Masitah Ahmad. 2018. Design for Songket Weaving in Malay Cottage Industry. In Proceedings of the 2018 CHI Conference Extended Abstracts on Human Factors in Computing Systems - CHI EA '18, 1-6. DOI: https://doi.org/10.1145/3170427.3188579 